Article

\title{
Changes in the Amino Acid Composition of Bogue (Boops boops) Fish during Storage at Different Temperatures by ${ }^{1}$ H-NMR Spectroscopy
}

Alessandra Ciampa ${ }^{1}$, Gianfranco Picone ${ }^{2}$, Luca Laghi ${ }^{1}$, Homa Nikzad ${ }^{3}$ and Francesco Capozzi ${ }^{1,4, *}$

1 Department of Food Science, University of Bologna, Piazza Goidanich 60, Cesena 47023 (FC), Italy; E-Mails: alessandra.ciampa2@unibo.it (A.C.); 1.laghi@unibo.it (L.L.)

2 Interdepartmental Centre for Industrial Agri-Food Research c/o Campus of Food Science, University of Bologna, Piazza Goidanich 60, Cesena 47521 (FC), Italy;

E-Mail: gianfranco.picone2@unibo.it

3 Department of Veterinary Medical Science, Alma Mater Studiorum-University of Bologna, Via Tolara di Sopra 50, 40064 Ozzano dell’Emilia (BO), Italy; E-Mail: homa.nik@alice.it

4 Center of Magnetic Resonance, University of Florence, Via L. Sacconi 6, Sesto Fiorentino 50019 (FI), Italy

* Author to whom correspondence should be addressed; E-Mail: francesco.capozzi@unibo.it; Tel.: +39-0547-338-105; Fax: +39-0547-382-348.

Received: 30 April 2012; in revised form: 4 June 2012 / Accepted: 11 June 2012 /

Published: 20 June 2012

Abstract: Nuclear magnetic resonance spectroscopy was employed to obtain information about the changes occurring in Bogue (Boops boops) fish during storage. For this purpose, ${ }^{1} \mathrm{H}-\mathrm{NMR}$ spectra were recorded at $600 \mathrm{MHz}$ on trichloroacetic acid extracts of fish flesh stored over a 15 days period both at $4{ }^{\circ} \mathrm{C}$ and on ice. Such spectra allowed the identification and quantification of amino acids, together with the main organic acids and alcohols. The concentration of acidic and basic free amino acids was generally found to increase and decrease during storage, respectively. These concentration changes were slow during the first days, as a consequence of protein autolysis, and at higher rates afterward, resulting from microbial development. Two of the amino acids that showed the greatest concentration change were alanine and glycine, known to have a key role in determining the individual taste of different fish species. The concentration of serine decreased during storage, as highlighted in the literature for frozen fish samples. Differences in the amino acids concentration trends were found to be related to the different storage temperatures from day 4 onwards. 
Keywords: fish; freshness index; ${ }^{1} \mathrm{H}-\mathrm{NMR}$; free amino acids (FAAs); quality assessment; metabolic profile; storage

\section{Introduction}

The amino acid composition of fish muscle proteins has been known for a long time to be remarkably constant across different species of fish [1]. Fish muscles contain from 1 to $5 \mathrm{~g}$ of free amino acids for every $100 \mathrm{~g}$ of protein, characterized by high quantities of taurine, histidine, glutamic acid, alanine, aspartic acid, leucine and lysine and by lower quantities of cysteine, tryptophan, methionine and tyrosine [2]. The pattern of free amino acid concentrations, rather than the composition of the amino acids bound to the proteins, is known to depend on the fish species. One of the reasons is that some free amino acids act as cell osmoregulators, so that their relative amount with respect to other free amino acids that are not involved in cellular osmotic regulation, can be modulated by the salt concentration in the fish habitat [1].

Concentration and pattern of free amino acids are also very sensitive to the changes occurring in fish muscle during storage. During the first hours following death such characteristics are modulated by autolysis, the degradation of muscle constituents by endogenous enzymes. This degradation is known to be $\mathrm{pH}$, temperature and fish processing dependent [3].

The $\mathrm{pH}$, decreasing upon death due to the transformation of glycogen into lactate, modulates the exit of the lytic enzymes from lysosomes. In this respect, it is of importance to note that catching methods that involve intense fish struggling lead to a greater transformation of glycogen into lactic acid, thus to a more powerful autolysis. The rates of these reactions are generally directly related to temperature, with an optimum around $36{ }^{\circ} \mathrm{C}$ for most of the lytic enzymes. Among the processing treatments able to modulate autolysis, evisceration may be of primary importance, as some proteolytic enzymes are known to be located in the gut [4].

The greatest modifications to the amount and pattern of free amino acids occur when the conditions are favorable for bacterial development. This phenomenon has contrasting effects on free amino acid concentrations as these molecules are extracted from proteins by lytic reactions and, in parallel, transformed into secondary products, some of which lead to malodors [5].

Autolysis and bacterial spoilage are responsible for changes occurring in the concentrations of adenosine-5'-triphosphate (ATP), adenosine-5'-diphosphate (ADP), adenosine-5'-monophosphate (AMP), and inosine-5'-monophosphate (IMP), which are quantitatively converted to inosine (HxR) and hypoxanthine $(\mathrm{Hx})[6,7]$. For this reason, all such molecules are often quantified to evaluate the quality loss during fish storage, and their relative amounts are combined together in a score to express fish freshness. One of the first conventional quality indices setup to take the degradation of such nucleotides into consideration is the $\mathrm{K}$ index [8], defined as

$$
\mathrm{K}(\%)=([\mathrm{HxR}]+[\mathrm{Hx}]) /([\mathrm{ATP}]+[\mathrm{ADP}]+[\mathrm{AMP}]+[\mathrm{IMP}]+[\mathrm{HxR}]+[\mathrm{Hx}])
$$

As free amino acids are key molecules in both autolysis and biological spoilage reactions, their observation may offer alternatives to the $\mathrm{K}$ index and its variants to follow fish quality loss during 
storage. Proton nuclear magnetic resonance $\left({ }^{1} \mathrm{H}-\mathrm{NMR}\right)$ can be in turn a suitable technique for this purpose, as suggested by recent papers published by some of the authors of the present work [9].

Picone et al. [10] observed free amino acids and other low molecular weight molecules using ${ }^{1}$ H-NMR to discriminate farmed specimens of Gilthead Seabream (Sparus aurata) according to the aquaculture system employed. Savorani et al. [11] employed NMR spectra to find out discriminant NMR intervals' spectra through $i$ ECVA [11,12], whilst Capozzi et al. [13] outlined a new algorithm that was able to correct the dilution errors during sample preparation affecting the quantification of serine, valine, histidine, phenylalanine and other amino acids.

Prompted by these encouraging results, we decided to apply ${ }^{1} \mathrm{H}-\mathrm{NMR}$ spectroscopy to monitor the changes occurring in the free amino acid pool during fish storage, to investigate the possibility of using such changes as storage quality indices. The fish chosen for the investigation belong to the Bogue (Boops boops) species, whose amino acidic composition is still uncharacterized in the literature, even if this species is commercially important and very popular in several Mediterranean countries [14,15].

\section{Experimental Section}

\subsection{Sampling}

All samples of Bogue fish, provided by Magna Grecia Mare-Portus Veneris (Leuca, Lecce, Italy), were caught in spring and brought to the laboratory in about ten hours, by means of polystyrene boxes filled with ice flakes. Ungutted fishes were divided into two groups. The first was stored at $4{ }^{\circ} \mathrm{C}$ and samples taken $0,2,4,6,8,10,11$ days after catching. The second group was stored on ice and sampled $0,2,4,6,8,10,15$ days after catching. The fishes were prepared for further processing by slicing them in a room at $4{ }^{\circ} \mathrm{C}$ and storing the flesh at $-80{ }^{\circ} \mathrm{C}$.

\subsection{Sample Preparation for ${ }^{1} H-N M R$ Analysis}

At each sampling time and temperature a trichloroacetic acid extraction (TCA) was performed on three fish samples, by following the procedure set up by Boland et al [16]. For this purpose, $25 \mathrm{~g}$ of fish muscle was added to $50 \mathrm{~mL}$ of $7.5 \%(\mathrm{w} / \mathrm{w})$ TCA and minced by means of a vertical homogenizer (Ultra-Turrax, $\mathrm{Ika}^{\circledR}$ ). The resulting product was filtered with filter paper (No. 4) from Whatman (Little Chalfont, Buckinghamshire, HP7 9NA, UK). The $\mathrm{pH}$ of a $1 \mathrm{~mL}$ aliquot was adjusted to 7.8 using $9 \mathrm{M} \mathrm{KOH}$ in an Eppendorf microfuge tube and centrifuged at $14 \mathrm{~K} \mathrm{rpm}$ for $5 \mathrm{~min}$ in order to remove potassium trichloroacetate precipitate. The so obtained supernatant was stored at $-80{ }^{\circ} \mathrm{C}$ until ${ }^{1} \mathrm{H}-\mathrm{NMR}$ measurements were performed.

\section{3. ${ }^{1} H-N M R$ Measurements}

The samples were prepared for NMR analysis by adding $160 \mu \mathrm{L}$ of a $\mathrm{D}_{2} \mathrm{O}$ solution of 3-(trimethylsilyl)-propionic-2,2,3,3-d4 acid sodium salt (TSP) $6.25 \mathrm{mM}$ to the thawed samples.

${ }^{1} \mathrm{H}-\mathrm{NMR}$ spectra were recorded at $298 \mathrm{~K}$ with a Bruker (Milano, Italy) AVANCE spectrometer operating at a frequency of $600.13 \mathrm{MHz}$, equipped with an autosampler with 60 holders.

Each spectrum was acquired using $32 \mathrm{~K}$ data points over a $7211.54 \mathrm{~Hz}$ spectral width and adding 256 transients. A recycle delay of $5 \mathrm{~s}$ and a $90^{\circ}$ pulse of $11.4 \mu$ s were set up. Acquisition time $(2.27 \mathrm{~s})$ 
and recycle delay were adjusted to be 5 times longer than the $\mathrm{T}_{1}$ of the protons under investigation, which has been considered to be not longer than $1.4 \mathrm{~s}$. Saturation of residual water signal was achieved by irradiating it during the recycle delay at $\delta$ equal to $4.703 \mathrm{ppm}$. Each spectrum was processed with MestReC 4.9.8.0 (Mestreab Research SL, Spain) by manually adjusting phase and base-line and applying a line broadening factor of $0.5 \mathrm{~Hz}$.

The peaks were assigned by comparing their chemical shift and multiplicity with the literature [11]. When peaks due to different protons of the same molecule were identified, both were employed for the quantification.

\section{Results and Discussion}

A typical ${ }^{1} \mathrm{H}-\mathrm{NMR}$ spectrum obtained during the present investigation is shown in Figure 1. Three groups of peaks could be identified. The peaks with the highest intensity, accounting for $30 \%$ of the total spectra area, pertain to trimethylamine- $N$-oxide (TMAO), trimethylamine (TMA) and creatine and phosphocreatine. In the region between 8.16 and $8.60 \mathrm{ppm}$ the peaks employed to calculate the $\mathrm{K}$ index could be identified. The remaining peaks could be mainly ascribed to amino acids and, to a minor extent, to organic acids and short chain fatty acids. At the chemical shifts of the amino acids sharp peaks could be identified, with a width at half height around $1 \mathrm{~Hz}$, which could be assigned to amino acids in the free form or pertaining to low molecular weight peptides. At the base of some of such peaks, macromolecules and aggregates gave rise to much broader signals, which could not be discriminated from the baseline noise. Such different behavior is caused by the inverse relationship existing between signal linewidth and (i) the nuclear relaxation rate, being shorter for slow tumbling macromolecules; and (ii) molecular anisotropy, being longer for denatured and disordered proteins [17].

Figure 1. $600.13 \mathrm{MHz}{ }^{1} \mathrm{H}$ NMR spectrum of TCA Bogue fish extract. The numbers refer to the assignments reported in Table 1.

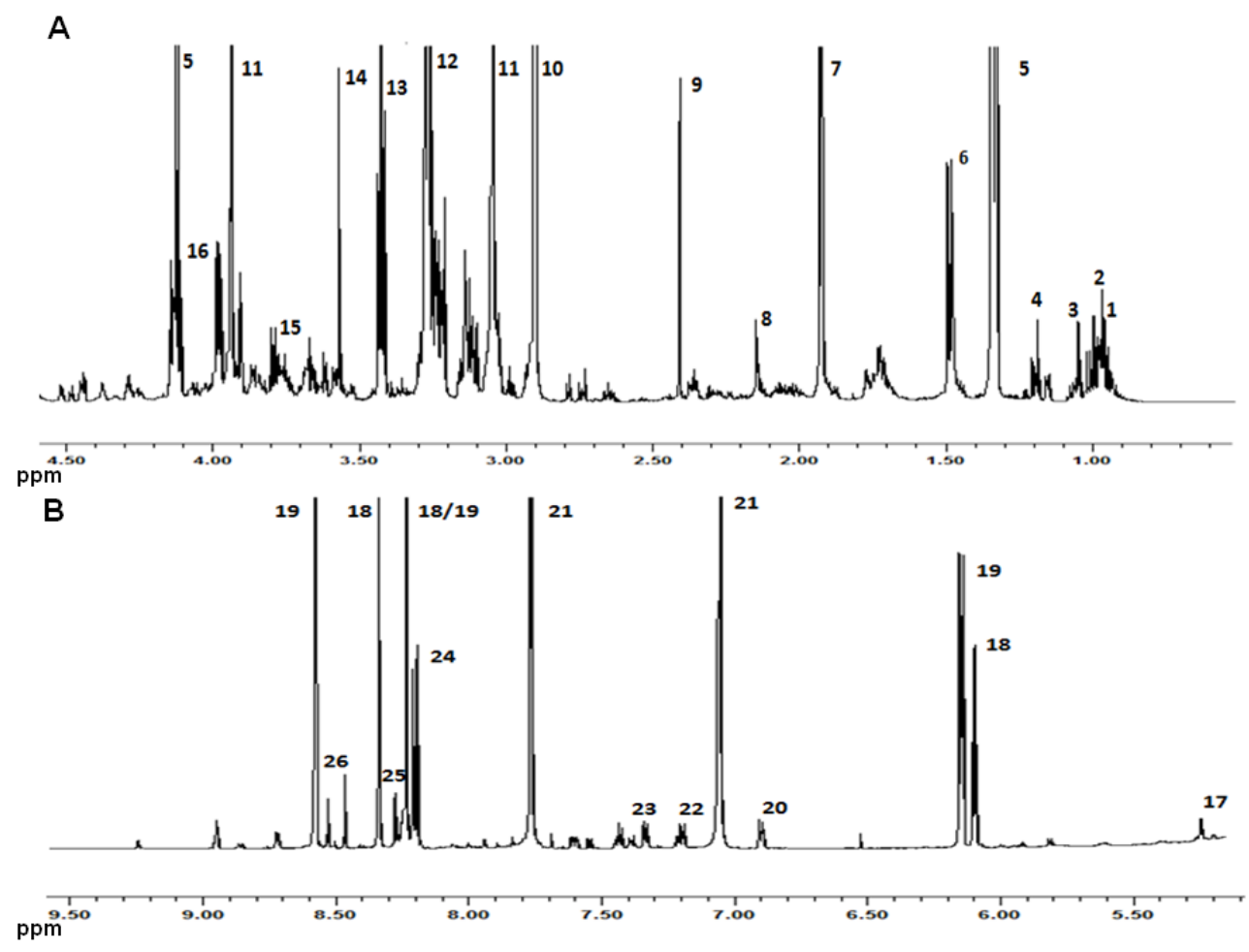


Table 1 lists the NMR signals of the amino acids involved in the fish spoilage during the present investigation. The resonances used in the integration were chosen from among those belonging to the corresponding signal multiplet which was found to be only marginally overlapping with other signals. Nevertheless, for some amino acids a clean signal was not found, and for this reason their variation was given in a cumulative way (e.g., Ile, Leu and Val) or not given at all (e.g., Lys and Pro). In addition, the table lists the assignments of other substances, whose concentration could help in understanding which phenomenon, autolysis or bacteria development, was mainly responsible for the identified fluctuations of the amino acid concentrations.

Table 1. Summary of the metabolites identified in the $600.13 \mathrm{MHz}{ }^{1} \mathrm{H}$ NMR spectrum of the aqueous extract of Bogue fish.

\begin{tabular}{|c|c|c|c|}
\hline Compound & Assignment & ${ }^{1} \mathbf{H}$ (ppm) & Multiplicity \\
\hline Isoleucine (Ile) $^{1}$ & $\delta-\mathrm{CH}_{3}$ & 0.94 & $\mathrm{t}$ \\
\hline Leucine (Leu) ${ }^{2}$ & $\delta^{\prime}-\mathrm{CH}_{3}$ & 0.96 & $\mathrm{~d}$ \\
\hline Valine $(\mathrm{Val})^{3}$ & $\gamma-\mathrm{CH}_{3}-\gamma^{\prime}-\mathrm{CH}_{3}$ & $1.00-1.05$ & $\mathrm{dd}$ \\
\hline Ethanol $^{4}$ & $\mathrm{CH}_{3}$ & 1.19 & $\mathrm{t}$ \\
\hline Lactate $(\mathrm{La})^{5}$ & $\beta-\mathrm{CH}_{3}$ & 1.33 & $\mathrm{~d}$ \\
\hline Alanine (Ala) ${ }^{6}$ & $\beta-\mathrm{CH}_{3}$ & 1.49 & $\mathrm{~d}$ \\
\hline Acetate $^{7}$ & $\mathrm{CH}_{3}$ & 1.93 & $\mathrm{~s}$ \\
\hline Methionine (Met) ${ }^{8}$ & $\mathrm{~S}-\mathrm{CH}_{3}$ & 2.14 & $\mathrm{~s}$ \\
\hline Succinate $^{9}$ & $\alpha, \beta-\mathrm{CH}_{2}$ & 2.41 & $\mathrm{~s}$ \\
\hline Trimethylamine ( $N$-TMA) ${ }^{10}$ & $\mathrm{~N}-\mathrm{CH}_{3}$ & 2.90 & $\mathrm{~s}$ \\
\hline Creatine/Phosphocreatine ${ }^{11}$ & $\mathrm{~N}-\mathrm{CH}_{3}$ and $\mathrm{N}=\mathrm{C}$ & 3.04 & $\mathrm{~s}$ \\
\hline Oxide Trimethylamine ( $N$-TMAO) ${ }^{12}$ & $\mathrm{~N}-\mathrm{CH}_{3}$ & 3.27 & S \\
\hline Taurin $(\mathrm{Tau})^{13}$ & $\mathrm{~N}-\mathrm{CH}_{2}$ & 3.42 & $\mathrm{t}$ \\
\hline Glycine (Gly) ${ }^{14}$ & $\alpha-\mathrm{CH}$ & 3.56 & $\mathrm{~s}$ \\
\hline Glutamate $(\mathrm{Glu})^{15}$ & $\alpha-\mathrm{CH}$ & 3.75 & $\mathrm{t}$ \\
\hline Creatine/Phosphocreatine ${ }^{11}$ & $\mathrm{~N}-\mathrm{CH}_{2}$ & 3.94 & $\mathrm{~s}$ \\
\hline Serine (Ser) ${ }^{16}$ & $\beta-\mathrm{CH}$ & 3.98 & $\mathrm{dd}$ \\
\hline$\alpha$-Glucose $(\alpha-\text { GLC })^{17}$ & $\mathrm{CH}-1$ & 5.24 & $\mathrm{~d}$ \\
\hline Inosine $(\mathrm{HxR})^{18}$ & CH-1', ribose & 6.10 & $\mathrm{~d}$ \\
\hline Inosine 5'-monophosphate (IMP) ${ }^{19}$ & CH-1', ribose & 6.14 & $\mathrm{~d}$ \\
\hline Tyrosine (Tyr) ${ }^{20}$ & $\mathrm{C}_{3,5} \mathrm{H}$, ring & 6.88 & $\mathrm{~d}$ \\
\hline Histidine (His) ${ }^{21}$ & $\mathrm{C}_{2} \mathrm{H}$ ring $/ \mathrm{C}_{4} \mathrm{H}$ ring & $7.06 / 7.77$ & $\mathrm{~s}$ \\
\hline Tryptophan (Trp) ${ }^{22}$ & $\mathrm{C}_{5} \mathrm{H}$ ring & 7.19 & $\mathrm{t}$ \\
\hline Phenylalanine (Phe) ${ }^{23}$ & $\mathrm{CH}-2,6$ & 7.32 & $\mathrm{~m}$ \\
\hline Hypoxanthine $(\mathrm{Hx})^{24}$ & $\mathrm{CH}-8$ & 8.19 & s \\
\hline Hypoxanthine $(\mathrm{Hx})^{24}$ & $\mathrm{CH}-2$ & 8.21 & $\mathrm{~s}$ \\
\hline Inosine $(\mathrm{HxR})^{18}$ & $\mathrm{CH}-8$ & 8.233 & $\mathrm{~s}$ \\
\hline Inosine 5'-monophosphate (IMP) ${ }^{19}$ & $\mathrm{CH}-8$ & 8.236 & $\mathrm{~s}$ \\
\hline \multicolumn{4}{|l|}{ Adenosine $5^{\prime}$-triphosphate (ATP) ${ }^{25}$} \\
\hline Adenosine 5'-diphosphate (ADP) ${ }^{25}$ & $\mathrm{CH}-8$ & 8.27 & $\mathrm{~s}$ \\
\hline \multicolumn{4}{|l|}{ Adenosine $5^{\prime}$-monophosphate (AMP) ${ }^{25}$} \\
\hline Inosine $(\mathrm{HxR})^{18}$ & $\mathrm{CH}_{2}$, ring & 8.33 & $\mathrm{~s}$ \\
\hline Formate $(\mathrm{Fo})^{26}$ & $\mathrm{CH}$ & 8.46 & $\mathrm{~s}$ \\
\hline Inosine 5'-monophosphate (IMP) ${ }^{19}$ & $\mathrm{CH}_{2}$, ring & 8.57 & $\mathrm{~s}$ \\
\hline
\end{tabular}


When the content evolution of a mixture has to be evaluated by comparing different spectra registered from different samples, the spectra cannot be directly compared, even when acquired with the same parameters as in the present case. Several factors are in fact known to alter the sensitivity of the instrument from sample to sample, leading to variations in the relationship between concentration of the analytes and the area of the corresponding peaks [18].

To avoid this source of error when measuring content evolution of a mixture, most often a referring standard is selected whose concentration is constant among the different samples. The spectra intensity is then scaled to this concentration, a procedure called "normalization" or vertical scaling [13].

When dealing with biological samples, it is common practice to employ the total area of the spectrum as a referring standard, assuming that all the substances interconvert to each other during storage, leading to an almost constant total area [19]. This option could not be utilized for the samples analyzed during the present investigation, as protein hydrolysis occurring during conservation led to a progressive increase of the spectral total area. The same phenomenon potentially influences the concentration of every molecule characterizing the samples, so that none of them could be confidently employed as an endogenous internal standard. Another possibility with biological samples consists in adjusting the spectral vertical scale to the area of an added molecule, the so-called added internal reference standard. When the investigated samples are liquids extracted from solids, the standard addition can only be in the last step of the sample preparation process. The relative area of the internal standard becomes thus sensitive to the variability induced by the extraction efficiency, which in turn is variable among samples undergoing time dependent structural degradation [20]. In addition, an added molecule may represent an unreliable concentration reference if interactions with macromolecules characterizing the sample occur [21].

An alternative to all the above mentioned normalization procedures can be offered by the presence of a small pool of metabolites known to be present in similar concentrations in every sample and known to belong to a closed inter-conversion pathway, so that their total molar amount can be considered as constant during storage. This is the case of the ATP degradation pathway, which in post mortem conditions is ultimately converted to hypoxanthine, via the by-products included in the calculation of the K-index [6]. To test the possibility of scaling towards the area of the peaks due to ATP and byproducts, a procedure we may call K-index normalization (KIN), the total area of these molecules was calculated on the raw spectra before normalization. In spite of the possible sources of error potentially affecting the spectra, the samples analyzed at the same storage times gave an average RSD of $3.3 \%$ and no statistically significant differences were found among the time points. The KIN method was thus elected as the normalization procedure for the present work.

Figures 2 and 3 present the fluctuation during storage on ice and at $4{ }^{\circ} \mathrm{C}$ of the molecules followed during the present investigation. The amino acids could be divided into three groups according to the trend of their concentration. The first group was represented by taurine only, whose concentration did not significantly change during storage. This was not unexpected, since this amino acid is not employed by organisms as a protein constituent, thus it is not involved in the lytic processes going on during autolysis reactions or bacterial development. Indeed, results in accordance with this observation can be found in the literature for several kinds of fishes and fish preparations, stored from $-20{ }^{\circ} \mathrm{C}$ [22] to $25{ }^{\circ} \mathrm{C}[23]$. 
Figure 2. Concentration changes relative to fresh samples of taurine, histidine and serine during storage at $4{ }^{\circ} \mathrm{C}$ (blue symbols and lines) and on ice (red symbols and lines).
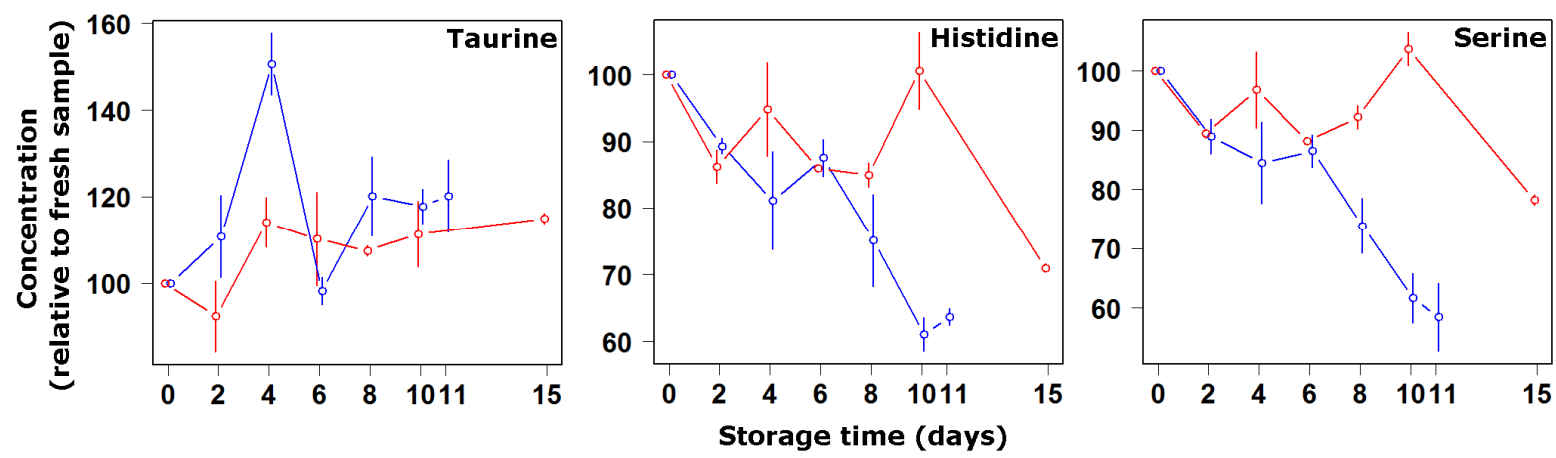

Figure 3. Concentration changes relative to fresh samples of alanine, phenylalanine, tryptophan, glycine, methionine, isoleucine-leucine-valine, tyrosine and glutamate during storage at $4{ }^{\circ} \mathrm{C}$ (blue symbols and lines) and on ice (red symbols and lines).
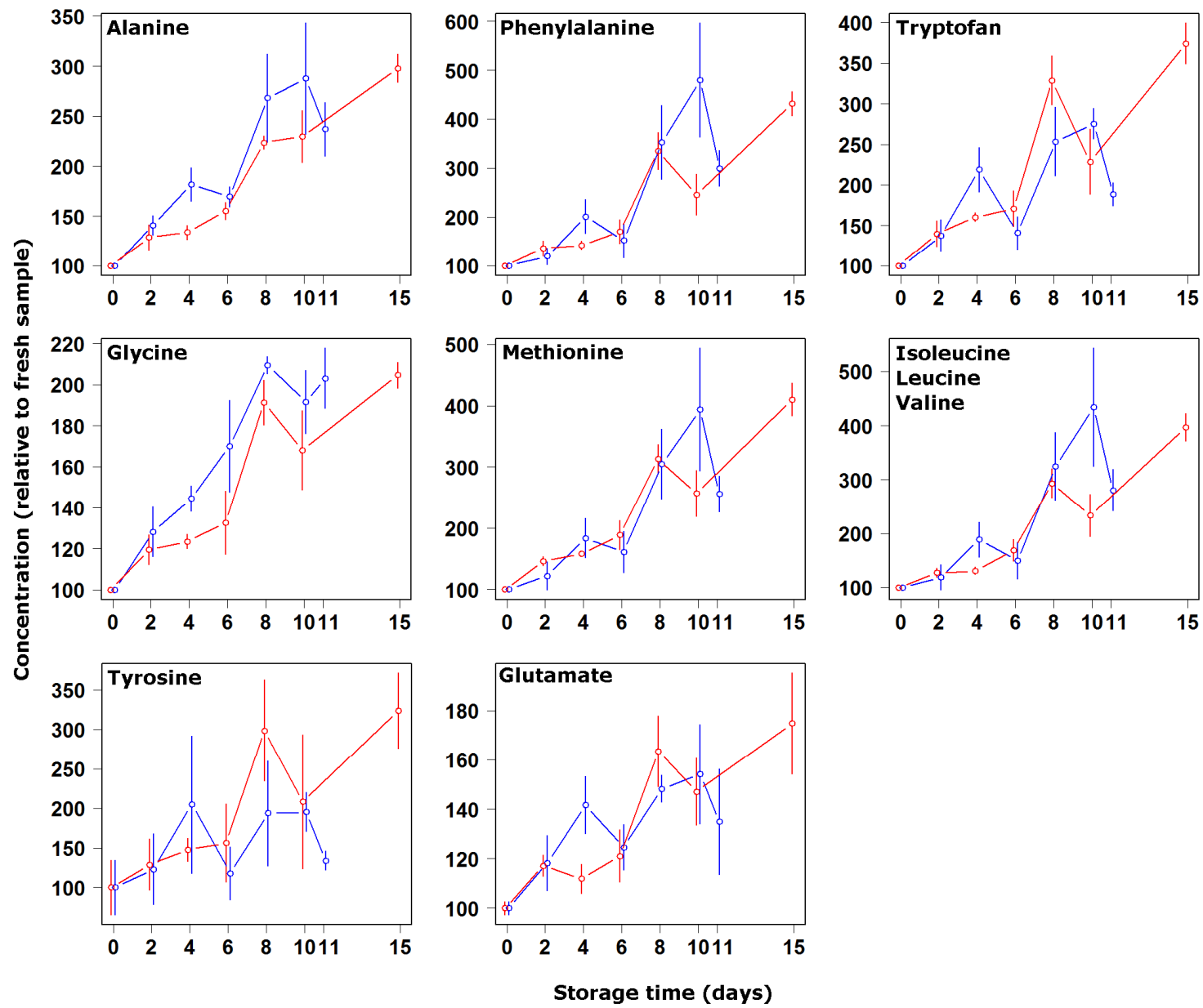

The second and third groups comprised the amino acids whose concentration increased and decreased, respectively, as a consequence of storage at $4{ }^{\circ} \mathrm{C}$. The former group was composed of alanine, phenylalanine, tryptophan, glycine, methionine, isoleucine-leucine-valine, tyrosine and glutamate, while the latter group was made up of histidine and serine only. The decrease in concentration of the basic amino acids shows that their solubilization from muscle proteins was slower 
than their transformation into byproducts, namely biogenic amines through decarboxylation. Such finding, together with the parallel increase of the acidic amino acids, is well documented at ambient temperature for a variety of fishes and transformed products based on them [24,25]. Kiesvaara [26] set up specific quality indices for salted herrings based on such knowledge. At room temperature, moreover, there is a general agreement about the decrease of methionine during storage [27]. The data collected for the present investigation seems to confirm the findings. Exceptions are represented by serine, which is acidic but decreases, and methionine, which increased in concentration at both investigated temperatures. Such trends appear to be more similar to those observed in the literature for frozen samples. As an example, Jiang et al. [22] found decreasing concentrations of serine in frozen samples of mackerel, amberfish, mullet and carp during storage, and at the same time an increasing concentration of methionine. The fact that at both temperatures the tested methionine did not decrease is interesting from a consumer perspective, as the catabolism of this amino acid is known to be primarily responsible for methylmercaptan and dimethylsulphide formation, molecules strongly related to development of off-flavors [28].

By focusing on the relationship between amino acid concentrations and storage time, it was possible to divide the observed molecules into two categories. The concentration of alanine, tryptophan, glycine methionine and tyrosine were observed to change during storage with a constant trend. In contrast, the other molecules seemed to be characterized by a slow change until day 4 and by a higher change rate afterwards. In this respect it must be noted that the concentration of some of the latter molecules, in particular histidine and serine, changed at similar rates in the two storage methods until day 4 , and at markedly different rates afterwards. Such a two-phase observation could be rationalized considering that the enzymes leading to autolysis are known to be poorly influenced by temperature, being still active even at temperatures as low as $-17{ }^{\circ} \mathrm{C}$ [3]. The slow rate change until day 4 can thus be considered mainly due to autolysis, the fast rate change occurring afterwards due to bacterial development. Indeed, the concentration of some of the mentioned molecules seem to reproduce a bacterial development curve [5] characterized by: (i) a lag phase in which the Bogue can be considered as fresh. During this phase the concentration of some amino acids undergoes fluctuations appreciated by the consumer in specific cases. Free glycine, for example, is known to be important for the individual taste of different fish species [29]; (ii) an exponential multiplication phase, typically characterized by development of off-flavors; and (iii) a stationary phase during which the concentration of some free amino acids start to decrease.

To confirm the findings based on the quantification of the free amino acids, other molecules involved in the microorganisms' development were quantified (Figure 4). Glucose and lactate are recognized as a substrate for most of the microorganisms involved in the spoilage of fish, glucose being consumed at first instance, followed by lactate and amino acids [30]. At the same time, acetate, succinate and ethanol typically accumulate in the medium, as a consequence of such development. Indeed, during the present investigation a $40 \%$ decrease of both glucose and lactate was noticed for the samples storage at $4{ }^{\circ} \mathrm{C}$, whilst acetate, succinate and ethanol increased from the fourth day in samples stored at $4{ }^{\circ} \mathrm{C}$ and after 15 days in the samples stored on ice. 
Figure 4. Concentration changes relative to fresh samples of lactate, glucose, acetate, succinate and ethanol during storage at $4{ }^{\circ} \mathrm{C}$ (blue symbols and lines) and on ice (red symbols and lines).
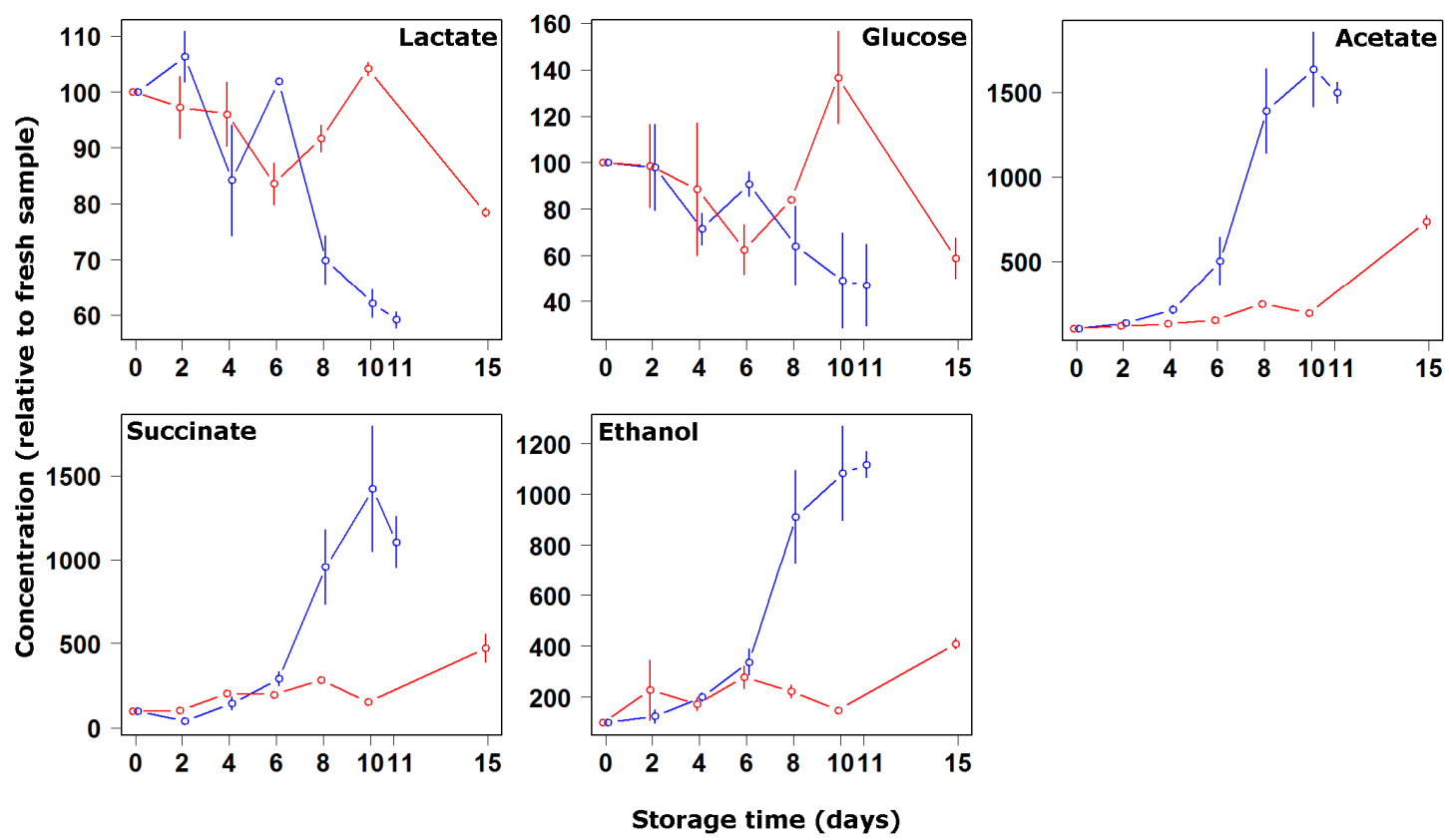

\section{Conclusions}

In the present work, changes of Bogue fish muscle composition were followed as a consequence of storage at $4{ }^{\circ} \mathrm{C}$ and on ice. For this purpose, ${ }^{1} \mathrm{H}-\mathrm{NMR}$ spectra were recorded on Bogue fish muscle TCA extracts and then normalized to the total area of the peaks pertaining to ATP and its degradation products. Through such amplitude adjustment, preferred to other kinds of vertical scaling procedures described in the literature, the effects of storage on the concentration of 13 amino acids in the free form could be registered. The concentration of some of them was observed to increase in the fish flesh as a consequence of enzymatic reactions, during the first days of storage, and due to bacterial development afterwards. Histidine concentration was observed to decrease, as a consequence of decarboxylation leading to histamine. The storage temperature seemed to mainly affect bacterial development rate, modulating the amino acid concentrations starting from day 4 of storage. The amino acids profile was shown to be sensitive to the phenomena leading to the compositional changes occurring during fish storage. Its evaluation, through ${ }^{1} \mathrm{H}-\mathrm{NMR}$ spectroscopy or other less expensive techniques, appears to be a promising source of parameters suitable for the assessment of freshness, as an alternative to the $\mathrm{K}$-index or analogue indices. It is important to stress here that NMR spectroscopy must be considered as a "non targeted" technique able to quantify and evaluate kinetics for unselected compounds, even a posteriori, e.g., after a pool of spectra is recorded on a population of samples and the multivariate analysis points out some interesting features in the molecular profile, that may be suitable for the development of new parameters related to quality and freshness. 


\section{Acknowledgments}

This work was supported by the Italian Ministry of Agricultural, Food and Forestry Policies (Italy) (MiPAAF "FreshFish" Project). "Fondazione Cassa di Risparmio di Cesena" is gratefully acknowledged for supporting the upgrade of the BioNMR lab and Carlo Martella for providing the Bogue fish samples.

\section{Conflict of Interest}

The authors declare no conflicts of interest relating to this manuscript.

\section{References}

1. Bramstedt, F. Amino acid composition of fresh fish and influence of storage and processing. In Fish in Nutrition; Heen, E., Kreuzer, R., Eds.; Fishing News (Books) Ltd.: London, UK, 1962; pp. 61-67.

2. Connell, J.J.; Howgate, P.F. The amino-acid composition of some british food fishes. J. Sci. Food Agric. 1959, 10, 241-244.

3. Mukundan, M.K.; Antony, P.D.; Nair, M.R. A review on autolysis in fish. Fish Res. 1986, 4, 259-269.

4. Voskresensky, N.A. Fish as Food; Academic Press: New York, NY, USA, 1965; Volume 3, pp. 107-131.

5. Gram, L.; Huss, H.H. Microbiological spoilage of fish and fish products. Int. J. Food Microbiol. 1996, 33, 121-137.

6. Mendes, R.; Quinta, R.; Nunes, M.L. Changes in baseline levels of nucleotides during ice storage of fish and crustaceans from the portuguese coast. Eur. Food Res. Technol. 2001, 212, 141-146.

7. Márquez-Ríos, E.; Morán-Palacio, E.F.; Lugo-Sánchez, M.E.; Ocano-Higuera, V.M.; Pacheco-Aguilar, R. Postmortem biochemical behavior of giant squid (Dosidicus gigas) mantle muscle stored in ice and its relation with quality parameters. J. Food Sci. 2007, 72, C356-C362.

8. Saito, T.; Arai, K.; Matsuyoshi, M. A new method for estimating the freshness of fish. Bull. Jpn. Soc. Sci. Fish. 1959, 24, 749-750.

9. Capozzi, F.; Cremonini, M.A. Nuclear magnetic resonance spectroscopy in food analysis. In Handbook of Food Analysis Instruments; Otles, S., Ed.; CRC Press: Boca Roton, FL, USA, 2008; pp. 281-318.

10. Picone, G.; Balling Engelsen, S.; Savorani, F.; Testi, S.; Badiani, A.; Capozzi, F. Metabolomics as a powerful tool for molecular quality assessment of the fish Sparus aurata. Nutrients 2011, 3, 212-227.

11. Savorani, F.; Picone, G.; Badiani, A.; Fagioli, P.; Capozzi, F.; Engelsen, S.B. Metabolic profiling and aquaculture differentiation of gilthead sea bream by ${ }^{1} \mathrm{H}-\mathrm{NMR}$ metabonomics. Food Chem. 2010, 120, 907-914.

12. Nørgaard, L.; Bro, R.; Westad, F.; Engelsen, S.B. A modification of canonical variates analysis to handle highly collinear multivariate data. J. Chemom. 2006, 20, 425-435. 
13. Capozzi, F.; Ciampa, A.; Picone, G.; Placucci, G.; Savorani, F. Normalization is a Necessary Step in NMR Data Processing: Finding the Right Scale Factors. In Magnetic Resonance in Food Science: An Exciting Future; Renou, J.P., Belton, P.S., Webb, G.A., Eds.; CRC Press: Cambridge, UK, 2011; pp. 147-160.

14. Özogul, Y.; Özogul, F. Fatty acid profiles of commercially important fish species from the mediterranean, aegean and black seas. Food Chem. 2007, 100, 1634-1638.

15. Koutsoumanis, K.; Nychas, G.-J.E. Chemical and sensory changes associated with microbial flora of mediterranean boque (Boops boops) stored aerobically at 0, 3, 7, and $10{ }^{\circ} \mathrm{C}$. Appl. Environ. Microbiol. 1999, 65, 698-706.

16. Boland, F.E. Trimethylammine nitrogen in seadfood method colorimetric. J. Assoc. Off. Anal. Chem. 1971, 54, 9.

17. Bordoni, A.; Picone, G.; Babini, E.; Vignali, M.; Danesi, F.; Valli, V.; Di Nunzio, M.; Laghi, L.; Capozzi, F. NMR comparison of in vitro digestion of Parmigiano reggiano cheese aged 15 and 30 months. Magn. Reson. Chem. 2011, 49, S61-S70.

18. Burton, I.W.; Quilliam, M.A.; Walter, J.A. Quantitative ${ }^{1} \mathrm{H}-\mathrm{NMR}$ with external standards: Use in preparation of calibration solutions for algal toxins and other natural products. Anal. Chem. 2005, 77, 3123-3131.

19. Ndagijimana, M.; Laghi, L.; Vitali, B.; Placucci, G.; Brigidi, P.; Guerzoni, M.E. Effect of a synbiotic food consumption on human gut metabolic profiles evaluated by $1 \mathrm{~h}$ nuclear magnetic resonance spectroscopy. Int. J. Food Microbiol. 2009, 134, 147-153.

20. Craig, A.; Cloarec, O.; Holmes, E.; Nicholson, J.K.; Lindon, J.C. Scaling and normalization effects in NMR spectroscopic metabonomic data sets. Anal. Chem. 2006, 78, 2262-2267.

21. Kriat, M.; Confort-Gouny, S.; Vion-Dury, J.; Sciaky, M.; Viout, P.; Cozzone, P.J. Quantitation of metabolites in human blood serum by proton magnetic resonance spectroscopy. A comparative study of the use of formate and tsp as concentration standards. NMR Biomed. 1992, 5, 179-184.

22. Jiang, S.T.; Lee, T.C. Changes in free amino acids and protein denaturation of fish muscle during frozen storage. J. Agric. Food Chem. 1985, 33, 839-844.

23. Je, J.-Y.; Park, P.-J.; Jung, W.-K.; Kim, S.-K. Amino acid changes in fermented oyster (Crassostrea gigas) sauce with different fermentation periods. Food Chem. 2005, 91, 15-18.

24. Ababouch, L.; Afilal, M.E.; Benabdeljelil, H.; Busta, F.F. Quantitative changes in bacteria, amino acids and biogenic amines in sardine (Sardina pilchardus) stored at ambient temperature $\left(25-28^{\circ} \mathrm{C}\right)$ and in ice. Int. J. Food Sci. Technol. 1991, 26, 297-306.

25. Özden, Ö. Changes in amino acid and fatty acid composition during shelf-life of marinated fish. J. Sci. Food Agric. 2005, 85, 2015-2020.

26. Kiesvaara, M. On the Soluble Nitrogen Fraction of Barrel-Salted Herring and Semi-Preserves During Ripening; Valtion Teknillinen Tutkimuskeskus: Espoo, Finland, 1975.

27. Love, R.M. The Chemical Biology of Fishes: Advances 1968-1977, with a Supplementary Key to the Chemical Literature; Academic Press: San Diego, CA, USA, 1980.

28. Herbert, R.A.; Shewan, J.M. Precursors of the volatile sulphides in spoiling north sea cod (Gadus morhua). J. Sci. Food Agric. 1975, 26, 1195-1202. 
29. Giannakourou, M.C.; Koutsoumanis, K.; Nychas, G.J.E.; Taoukis, P.S. Development and assessment of an intelligent shelf life decision system for quality optimization of the food chill chain. J. Food Prot. 2001, 64, 1051-1057.

30. Dainty, R.H. Chemical/biochemical detection of spoilage. Int. J. Food Microbiol. 1996, 33, 19-33.

(C) 2012 by the authors; licensee MDPI, Basel, Switzerland. This article is an open access article distributed under the terms and conditions of the Creative Commons Attribution license (http://creativecommons.org/licenses/by/3.0/). 